\title{
REVIEW
}

\section{Surgical techniques for the management of male infertility}

\author{
Natalya A Lopushnyan and Thomas J Walsh
}

Evaluation and surgical treatment of male infertility has evolved and expanded, now leading to more precise diagnoses and tailored treatments with diminished morbidity and greater success. Surgeries for male infertility are divided into four major categories: (i) diagnostic surgery; (ii) surgery to improve sperm production; (iii) surgery to improve sperm delivery; and (iv) surgery to retrieve sperm for use with in vitro fertilization and intracytoplasmic sperm injection (IVF-ICSI). While today we are more successful than ever in treating male infertility, pregnancy is still not always achieved likely due to factors that remain poorly understood. Clinicians treating infertility should advocate for couple-based therapy, and require that both partners have a thorough evaluation and an informed discussion before undergoing specific surgical therapies.

Asian Journal of Andrology (2012) 14, 94-102; doi:10.1038/aja.2011.62; published online 28 November 2011

Keywords: male infertility; testis; varicocele

\section{INTRODUCTION}

Infertility is defined as inability to conceive after one year of regular, unprotected intercourse and affects $15 \%$ of all couples. ${ }^{1,2}$ In those couples, approximately half are due entirely to the female factor, $20 \%$ due to the male factor and the remaining 30\% involving a combination of both. ${ }^{3,4}$ Given these statistics, all infertile couples require a thorough evaluation of both partners.

The causes of male infertility are widely varied, and are best evaluated by an expert in male reproductive health. Some causes of male infertility can be identified and reversed (or improved) with specific surgery or medication, while other causes can be identified but not reversed. The purpose of the male infertility evaluation is to: (i) identify and correct the reversible causes of male infertility with the goal of allowing a couple to conceive through intercourse, or with the least amount of technology; (ii) identify irreversible conditions that may be amenable to treatment with assisted reproductive technology (ART) using the male partners sperm; (iii) identify irreversible conditions in which the man's sperm are not available, in which case the couple may consider donated sperm or adoption; (iv) identify medical diseases that may be associated with infertility and require treatment; and (v) identify specific genetic causes of infertility that may be transmitted to and impact offspring.

Surgical management of male factor infertility has expanded in the last 15 years. In the past, there were few options for infertile men, not only due to the inability to treat infertility, but also because the evaluation of infertile patients was not sophisticated enough to distinguish the cause. Only a correct diagnosis of the anatomical, genetic or endocrine abnormality causing male infertility would lead to a successful treatment. With advances in both diagnostic and surgical modalities, progress of microsurgical and reproductive technology, and especially the introduction of intracytoplasmic sperm injection (ICSI), this field has been revolutionized. Today, men who could not initiate a pregnancy just a few years ago are able to father their biological children. This article will focus on the overview of the current surgical trends in treatment of male infertility.

\section{DIAGNOSTIC SURGERY}

Historically, the absence or low number of sperm in the ejaculate often precluded men from fathering their own genetic progeny and relegated couples to the use of donor spermatozoa insemination or adoption or childlessness. With the development of ICSI in the early 1990s, men with severe oligozoospermia or azoospermia have been able to father children following the injection of a single sperm into the cytoplasm of a single oocyte. ${ }^{5,6}$ In the years subsequent to the development of ICSI, we have learned that sperm retrieved directly from testicular tissue may also be used for oocyte fertilization and provide normal embryo development. Thus, in the evaluation of the azoospermic male, the key question is whether spermatogenesis is occurring in the testes and to what degree. Unfortunately, non-invasive testing has proven incapable of predicting which azoospermic men will actually harbor sperm within the testicle. ${ }^{7-9}$ Presently, the only reliable predictor of spermatogenesis is the histological or cytological identification of mature spermatozoa within sampled testicular tissue. ${ }^{8}$ In general, testicular tissue may be sampled for diagnostic purposes via two distinct methods: multi-site fine needle aspiration (or 'testicular mapping') and open testicular biopsy. 


\section{TESTICULAR BIOPSY}

\section{Indications}

Frequently, obstructive and non-obstructive azoospermia may be differentiated by patient history and physical examination. ${ }^{10,11}$ When non-obstructive azoospermia (NOA) is suspected or the clinical picture is unclear, a diagnostic biopsy or fine needle biopsy (FNA) is generally warranted to determine the presence or probability of retrieving mature sperm from the testes. Several histopathological findings may be present, with each caring a unique probability of retrievable spermatozoa (Table 1). ${ }^{12}$ In some circumstances, a testicular biopsy may be both diagnostic and therapeutic, whereby a biopsy segment, if found to have mature spermatozoa, may be cryopreserved for future use with ART.

\section{Technique}

Testicular biopsy may be done under general, spinal or local anesthesia. The latter is generally sufficient with the performance of a substantial spermatic cord block. Once adequate anesthesia is obtained, the scrotal skin is stretched over the testis and a small $1-2 \mathrm{~cm}$ transverse incision is made through the skin. Then tunica vaginalis is opened to expose the testis. The tunica albuguinea is incised $4-5$ $\mathrm{mm}$ in the least vascular area. The seminiferous tubules are extruded using gentle pressure, and a fine, sharp scissors are used to excise the tubules. The tunica is then closed with fine absorbable suture. Notably, spermatogenesis may not be equal between the testes or at all locations in each testis; therefore, in some circumstances, this procedure may be repeated at multiple different testicular sites.

\section{TESTICULAR FNA MAPPING}

\section{Indications}

Testicular FNA has been introduced as an alternative to the diagnostic testicular biopsy. Testicular FNA has been first described nearly half a century ago by Obrant and Persson in $1965,{ }^{13}$ but the use of FNA to 'map' spermatozoa within the testes was first described by Turek et al. in $1997 .{ }^{14}$ The procedure allows sampling of the tubules from various portions of the testis in a minimally invasive fashion. Several reports have shown that FNA provides tissue of the adequate quality and shows a good correlation with samples obtained via biopsy. ${ }^{14-16}$ The advantage of the FNA is the ability to sample several areas of the testes to identify potential 'pockets' of sperm. Further, FNA does not require incisions, has minimal morbidity ${ }^{17}$ and is the least invasive option for the initial evaluation of azoospermic men.

\section{Technique}

FNA may be done under local anesthesia and generally requires less than $1 \mathrm{~h}$ to complete a 24-site sampling template. After bilateral spermatic cord blocks are applied, the testis is stabilized in a subcutaneous position using an elongated gauze wrap. The sampling template is marked with ink and a $23 \mathrm{G}$ needle is passed through the stretched skin into testes after the epidermis is injected with local anesthetic. A negative pressure of $10 \mathrm{ml}$ is applied using a Cameco syringe adaptor to

Table 1 Testicular histology and success with surgical sperm retrieval $^{133}$

\begin{tabular}{lc}
\hline Histology & Successful \\
\hline Hyposperm retrieval rate (\%) \\
Maturation arrest (early) & $79-98$ \\
Maturation arrest (late) & 56 \\
Sertoli cell-only (pure) & 94 \\
\hline
\end{tabular}

Note: Adapted from Harris and Sandlow (133). acquire the specimen. Typically, 10-20 needle passes are required to obtain an adequate specimen, which is immediately discharged to a glass slide, crush, smeared and fixed in alcohol. Slides are then stained and analyzed for evidence of mature sperm as well as the overall histological pattern.

Although FNA is a less invasive technique, it does allow for sampling of multiple sites of the testis and has been shown to have $>90 \%$ histopathological correlation with testicular biopsy. ${ }^{16}$

\section{SURGERY TO IMPROVE SPERM PRODUCTION}

Varicocele is considered to be one of the most common correctable cause of male infertility occurring in up to $40 \%$ of evaluated men ${ }^{18}$ compared to $15 \%$ in the general population. The impact of varicocele on testicular function is thought to be progressive in nature, with semen parameters diminishing over time. ${ }^{19,20}$ The prevalence of varicocele in men with secondary infertility is higher compared to those evaluated for primary infertility. ${ }^{21,22}$ Mechanisms by which varicoceles affect spermatogenesis are not completely understood. The prevailing theories relate to impairment of the normal function of the venous (pampiniform) plexus that drains blood from the testicles. Dysfunction of these veins result in gravitational pooling of venous blood with concomitant loss of normal testicular temperature regulation. This phenomenon may also result in an altered testicular microenvironment. Several authors have reported the association between varicocele with elevated levels of reactive oxygen species leading to an increased oxidative stress and alteration of the normal acidbase balance. ${ }^{23,24}$

\section{Improvement in sperm parameters}

Semen parameters among infertile men with varicocele tend to exhibit abnormalities in concentration, morphology and motility, also known as a stress pattern. Most evidence supports that varicocele treatment causes improvements in semen parameters across variety of ages. ${ }^{25}$ The greatest improvement in semen quality appears to be in motility and morphology; ${ }^{26-28}$ however, most of the studies do not compare varicocelectomy patients with matched controls, comparing preoperative and postoperative sperm parameters of the same patients. Multiple reports have documented improvement in sperm counts after varicocelectomy with more benefit observed in men with sperm concentrations of $>10$ million $\mathrm{ml}^{-1} \cdot{ }^{29,30}$ Men with decreased testicular size persistently showed less of the improvement in sperm count, ${ }^{31-33}$ while higher grade and larger size of the preoperative varicocele was associated with greater improvement in semen quality. ${ }^{34,35}$ Initial work by McClure et al. $^{36}$ suggested that men with subclinical varicoceles were unlikely to demonstrate improved sperm count. This idea was confirmed by Jarow et al., ${ }^{35}$ who reported that men with subclinical varicocele were just as likely to have improved semen parameters as they were to have worsened parameters after the surgery.

Aside from improvement in the sperm motility, morphology and concentration, varicocelectomy has been shown to increase serum testosterone ${ }^{25,37}$ levels in men in their fifth and sixth decades suggesting potential benefit for treatment of hypogonadism for patients with baseline testosterone less than $400 \mathrm{ng} \mathrm{dl}{ }^{-1}\left(13.9 \mathrm{nmol} \mathrm{l} l^{-1}\right){ }^{25}$ Improvement in testosterone level was modest, with mean increase of $110 \mathrm{ng} \mathrm{dl}^{-1}\left(4.8 \mathrm{nmol} \mathrm{l}^{-1}\right)$ postoperatively. Improvement in testosterone and decreased levels of follicle-stimulating hormone (FSH) following microscopic varicocelectomy were also reported by other authors. ${ }^{38}$ There is lack of literature, however, correlating FSH levels after varicocelectomy with improved pregnancy rates. 
In management of adolescent varicocele, preservation of future fertility is the goal of treatment. Given that $80 \%$ of the adult males with varicocele are fertile, less aggressive approach in adolescents has been advocated. ${ }^{39}$ Testicular growth retardation with volume discrepancy of more than $20 \%$ compared to the contralateral testis is the most common indication for treatment, ${ }^{40}$ with several authors reporting catch-up growth after varicocelectomy. ${ }^{41,42}$

\section{Effects on conception}

Debate continues as to whether varicocelectomy improves fertility. ${ }^{43-45}$ Conflicting opinions prompted a Cochrane systematic review by Evers et $a l^{46}$ in 2008 and the meta-analysis by Marmar et al. ${ }^{47}$ The former review included eight randomized control trials of men with varicocele from couples with subfertility, and reported pregnancy rates as the outcome measure. Both clinical and subclinical varicoceles were included, some of whom had normal semen parameters. The analysis indicated no evidence of improved fertility and increased chances of conception. A meta-analysis by Marmar et al. included both RCTs and observational studies and only considered publications which included men with palpable varicoceles and at least one abnormal sperm parameter, thus more accurately reflecting the standard of care for infertile men. Only 'natural or spontaneous' pregnancies were considered. Based upon statistically significant improvements in pregnancy rate after varicocele ligation, the authors concluded that varicocelectomy was an effective treatment for couples with an infertile male with at least one abnormal semen parameter and a palpable varicocele. Odds of spontaneous pregnancy after varicocelectomy were reported at 2.63.

Data on pregnancy rates after varicocelectomy in men with azoospermia are controversial and mostly limited to the small case series. In a recent meta-analysis, Weedin and colleagues ${ }^{48}$ have determined that men with late maturation arrest and hypospermatogenesis had a better probability of success. As the conclusion, authors have recommended considering histopathological evaluation prior to varicocelectomy in that group.

While most reports publish rates of spontaneous pregnancies, fewer report the percentage of live birth following the varicocele repair. In the article by Lukkarinen et al., ${ }^{49} 31 \%$ of couples undergoing varicocelectomy for infertility were able to conceive, although only $26 \%$ achieved life birth uncomplicated by spontaneous abortion.

Female age certainly should play a role in the decision to proceed with varicocele repair. It has been reported that spontaneous pregnancy rates from women aged $<35$ were higher $(35.7 \%)$ compared with women age 35 years and older $(23.6 \%) .{ }^{50}$ In couples with primary and secondary infertility and a known varicocele, the most significant factor was advanced female age in the latter. ${ }^{51}$ These reports are consistent with current best practice guidelines ${ }^{52}$ which suggest that varicocelectomy should be offered to men who meet these criteria: (i) the varicocele is palpable; (ii) the couple has documented infertility, in which female factors are absent or correctable; and (iii) the man has two or more abnormal semen analyses.

\section{Surgical technique}

The goal of varicocele repair is to ligate or thrombose veins which are contributing to the varices as well as others that have a potential to cause varices in the future, while preserving adequate venous drainage, arteries, vas and lymphatics. The surgical technique has evolved since first described by Palomo in $1949 .{ }^{53}$ The original high retroperitoneal technique required a transverse incision to be made at the level of the internal inguinal ring and carried down through all the muscle layers. The peritoneum was then reflected medially and the muscles retracted cephalad to expose internal spermatic vessels. The internal spermatic vein was then ligated with permanent ties. This approach has been associated with varicocele recurrence up to $15 \%$ in adults and up to $45 \%$ in children. One disadvantage of this approach is the potential failure to ligate the cremasteric vessels, which could contribute to the high recurrence rates.

Laparoscopic repair is similar to retroperitoneal with a different surgical approach. The technique is not recommended for adults due to the frequent testicular artery ligation; however, theoretically testicular atrophy should not occur due to the collateral blood supply to the testis through cremasteric and vasal arteries. Nonetheless, every effort should be made to preserve all arterial sources of the testis.

Inguinal and subinguinal approaches are now the preferred techniques for varicocele repair. In the inguinal approach, an incision just above the external ring is carried down to the external oblique aponeurosis, which is incised. The illioinguinal nerve is identified then the spermatic cord is isolated and elevated to the surface of the incision with a Penrose drain. In the subinguinal approach, a transverse incision is made just below the level of the external inguinal ring. It is carried down through Scarpa's fascia to where the cord emerges from the external ring. The cord is identified, mobilized and brought to the surface of the incision with Penrose drain. A surgical microscope is utilized to identify, isolate and ligate individual varices (Figure 1). The microsurgical repair has the advantage of providing clear visualization of veins, arteries and lymphatics, thus significantly decreasing complications such as hydrocele formation, varicocele recurrence and testicular artery injury (Table 2). Testicular artery injury is rare and is reported to occur in $1 \%$ of the cases of microsurgical varicocele repair, with testicular atrophy being even more rare, affecting approximately $5 \%$ of the men with ligated testicular artery. ${ }^{54}$

Percutaneous embolization offers a minimally invasive approach and includes the traditional retrograde technique and the more recently described antegrade embolization. ${ }^{55,56}$ Complications include thrombophlebitis, epididymo-orchitis, arterial puncture, infections, varicocele persistence and contrast reaction, and are lower for

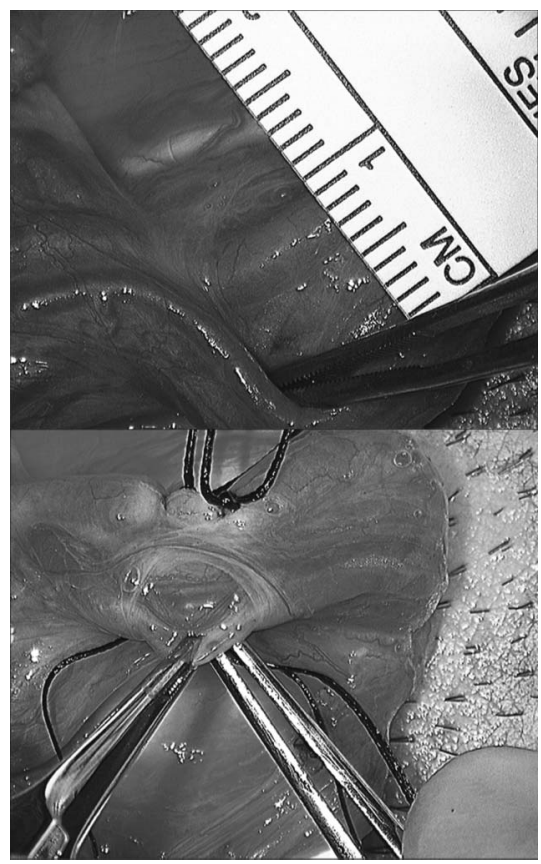

Figure 1 Subinguinal, microscopic approach to varicocele ligation. 
Table 2 Hydrocele formation and varicocele recurrence rate for various varicocelectomy techniques ${ }^{134}$

\begin{tabular}{llcr}
\hline Technique & Artery preserved & Hydrocele formation \% (range) & Recurrence \% (range) \\
\hline Retroperitoneal & No & $7.58(4.9-9.0)$ & $12.5(7.3-15.5)$ \\
Conventional inguinal & No & $7.47(4.3-17.5)$ & $15.6(3.6-17.5)$ \\
Laparoscopic & Yes & $7.6(1.7-12.7)$ & $11.1(4.0-26)$ \\
Radiographic & Yes & 0 & $4.3(1.9-9.3)$ \\
Microsurgical subinguinal & Yes & $0.72(0.3-1.6)$ & $2.1(1.4-14.8)$ \\
Microsurgical inguinal & Yes & $0.29(0.0-0.7)$ & $9.47(0.7-15.2)$ \\
\hline
\end{tabular}

the antegrade approach. ${ }^{57-59}$ Percutaneous approach is most useful in recurrent varices; when the anatomy needs to be delineated radiographically, however, it is highly operator-dependent. The imaging modality used in percutaneous embolization may eliminate the need for difficult surgical dissection in the previously operated field and allows for identification of persistently patent refluxing veins. Using newer described techniques and sclerosing foams, the contact between the vessel wall and the sclerosing agent is increased, diminishing the washout by blood within the vessel. ${ }^{60}$

\section{SURGERY TO IMPROVE SPERM DELIVERY}

Despite the intention of vasectomy to be permanent, approximately $6 \%$ men will desire to have it reversed. ${ }^{61}$ For a man who desires restoration of the fertility after vasectomy, there are two options for having a biologic child: vasectomy reversal or sperm extraction with in vitro fertilization and ICSI (IVF-ICSI). The choice of whether to proceed with surgical repair or testicular sperm extraction and IVF-ICSI should be made carefully by both the treating physician and the couple, and is influenced by multiple factors such as interval since vasectomy, female factors and cost. ${ }^{62}$

Female age has been determined to be an independent predictor for the pregnancy rate following vasectomy reversal, with women aged 40 years and older having lower rate of pregnancy. ${ }^{63,64}$ Cost effectiveness plays an important role in couple decision making given that vasectomy reversal and ART are often not covered by the insurance companies. In the report by Hsieh, ${ }^{65}$ authors showed that female age had a greater effect on cost than obstructive interval. However, in the United States context, if a couple is willing to reach a threshold cost of $\$ 65000$, the use of ART may be more effective in achieving pregnancy more quickly. Techniques for sperm retrieval are discussed in subsequent sections.

\section{Factors predicting success}

Despite the frequency with which vasectomy reversal is performed, it continues to be a highly technical procedure. Since first described by Silber, ${ }^{66}$ microscopic vasal anastomosis has become preferred technique to achieve a high rate of success. Aside from the technical skills of the surgeon, the interval since vasectomy is a key factor in the success of vasectomy reversal. A decline in the success of vasectomy reversal appears to occur around 10 years from the time of vasectomy ${ }^{67,68}$ and likely is related to the increased need for vasoepididymostomy (VE) due to secondary epididymal obstruction. ${ }^{69}$ A previous failed vasectomy reversal is not a contraindication to the vasovasostomy (VV) or VE, as patency can still be achieved in up to $79 \% .^{70}$ The absence of prior fertility in patients desiring vasectomy reversal is not frequent, but when encountered should raise a question of an abnormal spermatogenesis and further endocrine evaluation.

\section{Vasovasostomy (VV)}

$\mathrm{VV}$ is the surgical anastomosis of testicular and abdominal ends of the severed vas. Microsurgical repair, although requiring specific surgical skills, provides significant improvements in patency and pregnancy rates compared to macroscopic anastomosis. ${ }^{71,72}$ A recent comparison of one layer microscopic vs. loupe-assisted VV found the former to significantly superior with $96 \%$ vs. $72 \%$ relative patency. ${ }^{73}$ Pregnancy rate has been reported to vary depending on the interval since vasectomy with $76 \%$ if the interval was less than 3 years and decreasing to $30 \%$ for 15 years or longer. ${ }^{68}$ Mean interval to pregnancy following VV has been reported to be 17 months with $53 \%$ pregnancy rate. ${ }^{74} \mathrm{~A}$ variation of microsurgical instruments may be used depending on the surgeon's preference. Anastomosis is performed either in a multi-layer or a modified one-layer fashion with virtually equal patency results (Figure 2) ${ }^{75,76}$ During vasal isolation, an adequate length of vas on both sides is required for a tension-free anastomosis. Surrounding adventitia should be preserved to minimize ischemia and subsequent occlusion. Precise approximation of the lumens is required to achieve the best patency results and minimize sperm leak and granuloma formation. Suturing is generally performed with a double-arm 10-0 for luminal stitches and 9-0 nylon for the seromuscular layer.

The vasectomy site is identified and vas is dissected both proximal and distal. A healthy area of the vas is transected with the use of microscope and the fluid from the testicular end of the vas is examined for the presence of sperm. Intraoperative examination of the vasal fluid should be considered routine as fluid contents should guide intraoperative management. If sperm is absent or fluid is thick and pasty, secondary epididymal obstruction should be suspected and VE should be considered. This technique is discussed below. Given the highly technical nature of $\mathrm{VE}$, if there is preoperative concern for epididymal obstruction, then specialty referral or preoperative counseling related to sperm retrieval and IVF-ICSI should be considered. If sperm is not present in vasal fluid, testis biopsy can be performed for the purpose of sperm retrieval and confirmation of spermatogenesis. Patency and pregnancy rates vary with the quality of sperm observed in the fluid from the transected testicular portion of the vas with $>90 \%$ of men having return of sperm in the ejaculate if sperm was present in the vasal fluid on microscopic intraoperative examination. ${ }^{68,77}$ In a modified one-layer VV, a 9-0 suture is used for the full thickness anastomosis of the vasal wall and then adventitia is approximated. Various techniques may be used to increase luminal visualization and precision of suture placement, including the application of blue dye, viscoelastic gel and microdots. ${ }^{78,79}$ After vasectomy reversal, patient is advised to

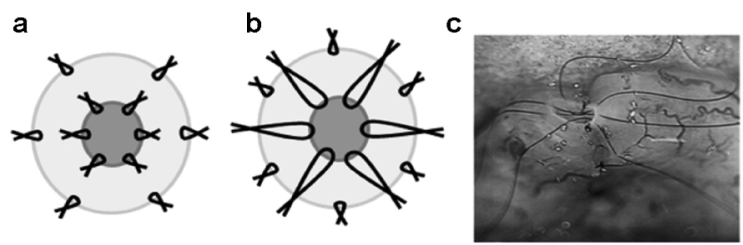

Figure 2 (a) Two-layer vasovasostomy and (b) modified one-layer vasovasostomy (c) 10-0 nylon luminal stiches are placed in a two-layer vasovasostomy. 
abstain from sexual activity for 2 weeks. He should return for a semen analysis at 6 weeks and then every 3 months for 1 year.

\section{Vasoepididymostomy (VE)}

VE was first described by Edward Martin and colleagues in 1902 with side-to-side anastomosis of the vas to the open epididymal tubule. ${ }^{80}$ This method and its modifications remained a gold standard of VE until Silber ${ }^{81}$ described a microsurgical anastomosis of the end of the vasal lumen to the transversely cut epididymal tubule. VE was further revolutionized by Berger ${ }^{82}$ in 1998 with the intussuscepted VE.

A VE is usually performed based on the intraoperative findings and microscopic examination of fluid that emerges from the testicular vas. Prior to the surgery, a need for VE may be anticipated based on prior history of failed VV, the interval since the vasectomy and the apparent site of vasectomy. As reported by Thomas, ${ }^{83}$ longer interval since vasectomy lead to a higher rate of VE with no VEs performed if vasectomy interval was less than 3 years and $43 \%$ of patients requiring $\mathrm{VE}$ after 14 years. Given that some surgeons only offer VV to their patients due to the technical difficulty of the VE, suspicion of the need for VE based upon preoperative clinical characteristics should prompt a referral to an experienced VE surgeon or even an IVF specialist given the availability and patient preference.

Technique. Once the decision to proceed with a VE is made, the epididymis is examined under the microscope to identify the point of obstruction. Using the highest level of optical magnification, two or three 10-0 sutures are preplaced in a protuberant epididymal tubule that is inspissated with sperm. The tubule is incised or punctured and the fluid is examined for motile sperm. If no sperm is present, a different and often more proximal tubule is identified and the process repeated. Once a healthy and full epididymal tubule is identified, the transected vas is anchored to the tunica of the epididymis and the preplaced epididymal sutures are brought through the mucosal layer of the vas to create an intussuscepted anastomosis. 9-0 nylon sutures are used to secure the epididymal tunic to the seromuscular vas. Patency rates for VE are reported to be $48 \%-63 \%$ with pregnancy rates of $21 \%-45 \%$ with mean interval to pregnancy of 16 months; ${ }^{74}$ however, a great variation exist depending on the surgeon. ${ }^{84-86}$

\section{Robotic assisted vasectomy reversal}

Most recently, the advances in technology such as DaVinci robotic platform have entered the field of infertility management. First described in animal studies, ${ }^{87} \mathrm{VV}$ and VE have now been performed in humans with promising results. Although data on overall benefit are limited, robotic assistance may offer increased precision and decreased operative time. $^{88}$

\section{Ejaculatory duct obstruction}

Approximately $1 \%-5 \%$ of male infertility is associated with ejaculatory duct obstruction (EDO). ${ }^{89}$ The causes are varied and are generally divided into acquired (seminal vesicle calculi, inflammatory or postsurgical changes) or congenital (atresia of the ducts, utricular or diverticular cysts). The defining feature of infertile men with EDO is low ejaculate volume $(<1.5 \mathrm{ml})$. Other characteristics may include low $\mathrm{pH}$ $(<7.2)$ and the absence of fructose in seminal fluid. In men with partial EDO, significant decrease in sperm motility and oligozoospermia may be present along with normal testicular exam and hormone profile.

Historically, vasography was used for diagnosis of the EDO ${ }^{89}$ Due to the potential risks of vasal injury and occlusion and relatively invasive nature of the vasography, it has been largely replaced by transrectal ultrasound as a standard diagnostic modality. Findings consistent with diagnosis of EDO are dilated seminal vesicles $(>1.5 \mathrm{~cm})$ or dilated ejaculatory ducts $(>2.3 \mathrm{~mm}) .^{90,91}$

Transurethral resection of ejaculatory ducts is the primary treatment for the EDO. First described by Farley and Barnes, ${ }^{92}$ it is a timeproven method which is usually done in an outpatient setting. A $24 \mathrm{Fr}$ resectoscope is used to resect the verumontanum with one or two cuts, or until the efflux of the copious cloudy fluid is noted from the unobstructed ejaculatory ducts. The use of concomitant transrectal ultrasound and chromotubation of the seminal vesicles can aid the resection. During chromotubation, $5 \mathrm{ml}$ of indigo carmine or methylene blue diluted with normal saline 1:5 are injected in an antegrade fashion transrectally into each seminal vesicle. ${ }^{93}$ During cystoscopy, the absence of dye emission at the verumontanum is consistent with EDO. Electrocautery is used judiciously to prevent scarring of the opened ducts. Reported improvement in semen after ejaculatory duct resection varies and may be better in men with partial obstruction, $94 \%$ vs. $59 \%{ }^{94}$

Complications rates have been reported to vary from $0 \%$ to $20 \%$ of the cases and include reflux of urine into the ejaculatory ducts, seminal vesicles and vas deferens, acute or chronic epididymitis, bleeding, recurrent stenosis, hematuria, retrograde ejaculation and bladder neck injury. ${ }^{95-97}$

\section{SURGERY TO RETRIEVE SPERM}

Azoospermia is defined as the absence of spermatozoa in at least two centrifuged samples of ejaculate. It is observed in $1 \%$ of general population and about $10 \%$ of infertile men. ${ }^{98,99}$ Patients with azoospermia have either obstructive (OA) or non-obstructive (NOA) pathology. While OA stems from the obstruction of the genital ducts, the lack of sperm in the NOA is due to testicular failure and affects $60 \%$ of the azoospermic men. ${ }^{100}$ In most cases, clinical and endocrine parameters do not definitively distinguish NOA from OA, making histopathology a requirement (see the section on 'Diagnostic surgery'). ${ }^{101}$ There are, however, more obvious cases where diagnostic surgery can be avoided. Schoor et al. ${ }^{101}$ proposed examining testicular axis and FSH levels. In their report, $96 \%$ of men with OA had FSH level $7.6 \mathrm{mIU} \mathrm{ml}^{-1}$ or less or long testicular axis $4.6 \mathrm{~cm}$ or greater and $89 \%$ of men with NOA had FSH greater than $7.6 \mathrm{mIU} \mathrm{ml}^{-1}$ and axis less than $4.6 \mathrm{~cm}$. Even though there is still a large overlap between two groups, frequently requiring tissue diagnosis.

Since the introduction of ICSI in 1992, the number of sperm required to achieve in vitro fertilization has decreased from thousands to theoretically just one. Further, the technique has allowed fertilization of an egg using sperm with limited intrinsic fertilizing capacity. The technique for sperm retrieval for IVF-ICSI depends mostly on the clinical picture of the patient and should be tailored accordingly. Ultimately, ideal surgical technique for sperm retrieval would retrieve a sufficient number of spermatozoa to fertilize all the available oocytes, with minimal trauma to the testes, and could be repeated multiple times in cases of unsuccessful ART cycle.

\section{Testicular sperm aspiration (TESA)}

For men in whom spermatogenesis is thought to be unaffected or at least present, TESA may be performed, usually with only local anesthesia. Depending upon the clinical circumstances and the consistency of the testicular tissue, the sperm amount may or may not be adequate for cryopreservation, but is generally sufficient for the fresh cycle of IVFICSI. Belker et al. ${ }^{102}$ have described an effective method of sperm aspiration in men with both types of azoospermia. A 1.5-inch, 
20-gauge needle attached to a $20 \mathrm{ml}$ syringe is used. Once testis is prepared and appropriate anesthesia, usually a cord block, is performed, the testis is punctured and negative pressure is exerted on the syringe primed with nutrient medium. The needle is moved back and forth four to five times in different directions without removing it from the site of puncture. The negative pressure is then reduced over 30-60 s and the needle is withdrawn. Any tubules protruding from the puncture site are transferred to a small plate or tube with a sperm nutrient medium. The needle is flushed with air also into a tube with the nutrient medium. A modification of this technique utilizes a 16-gauge angiocatheter rather than a needle for seminiferous tubule extraction. Via this modality, a larger volume of testicular tissue can be extracted via a single puncture with theoretically less risk of vascular injury.

Authors of the original technique have performed TESA on men with both $\mathrm{OA}$ and NOA achieving significantly better sperm retrieval results in men with OA, $100 \%$ vs. $27 \%$, respectively. It has been since shown to be more successful in patients with NOA, especially if repeated attempts for sperm aspiration are made, showing a cumulating rate of sperm retrieval of $67 \%$ after $1-4$ attempts. ${ }^{103}$ Not surprisingly, the best predictor of sperm retrieval was prior sperm retrieval, with only $11 \%$ of patients with prior negative result having a successful procedure.

\section{Testicular sperm extraction (TESE)}

Originally, TESE was introduced an alternative to epididymal sperm in men with OA for the purpose of IVF without a possibility for surgical repair. ${ }^{104}$ TESE differs from TESA in that it requires an incision to reach the testicular tissue. Many consider TESE to be a general term that encompasses all forms of testicular sperm retrieval of which TESA and MicroTESE (below) are subtypes. Successful TESE, like TESA, has been reported in men with NOA. ${ }^{105,106}$ Today, it is the most frequently used technique for sperm extraction in NOA men with a mean sperm recovery rate of $49.5 \% .{ }^{107}$ TESE with multiple biopsies was proposed as a way to enhance a sperm retrieval rate of a single biopsy, given that only sparse areas of spermatogenesis are present in patients with NOA. ${ }^{108}$

Although TESE is able to offer a larger area of sampling, it has been reported to cause a decrease in seminiferous tubular volume and have at least a transient effect on the spermatogenesis. ${ }^{109}$ Repeat TESE has been found to be progressively more difficult with the requirement for more biopsy sites to achieve adequate sperm retrieval. ${ }^{110}$ Given these issues, some authors recommending at least 6-month period between repeat procedures. ${ }^{111}$

Technique. The procedure itself is fairly straightforward and the objective is to take multiple mini-biopsy specimens from the testis. Once hemiscrotum is opened and the testis is brought to the surface of the incision, the initial incision is made horizontally in the tunica albuguinea in order to avoid major blood vessels. Expressed tissue is excised sharply and placed in the sperm nutrient medium. Process is repeated several more times in other areas of the testis with every biopsy being about $50 \mathrm{mg}$ in weight. Incision sites are closed with absorbable or permanent suture.

\section{MicroTESE}

First described by Schlegel and $\mathrm{Li}^{112}$ in 1998, microdissection TESE (microTESE) has become one approach for sperm extraction in men with NOA. In comparison with conventional TESE, microTESE has a significant learning curve, and requires proficiency in microsurgical techniques and a longer operative time. The technique relies upon the magnifying ability of a surgical microscope to allow identification of the individual seminiferous tubules that are engorged with sperm. The primary advantage of microTESE is the ability to examine and sample both testes in their entirety for the presence of sperm. As such, this technique appears to offer the most comprehensive search for sperm in the testis of men with NOA. ${ }^{113}$ Although there is a very low rate of complications with microTESE, the technique does require complete delivery of the testicles into the wound and bivalving of the testes to expose the seminiferous tubules. Thus, this technique is undoubtedly more invasive than others.

Since the introduction of the microTESE, several reports have described improved sperm recovery rate. ${ }^{114-116}$ Most of the reports did not, however, have matched groups of conventional TESE and microdissection patients. Histopathology also seems to influence sperm retrieval in microTESE compared to other techniques, with some authors reporting improvements only in Sertoli cell-only syndrome, Kleinfelter's syndrome, hypospermatogenesis and small testicular volume. ${ }^{114,117,118}$ Successful microTESE as a salvage procedure in cases of failed TESE has been reported. ${ }^{19-121}$ This more laborious procedure carries a longer operating time of $147 \mathrm{~min} v \mathrm{~s} .68 \mathrm{~min},{ }^{122}$ with the highest chance of sperm retrieval being in the first $2 \mathrm{~h} .{ }^{123}$ The same study, however, noted that even microTESE lasting in excess of $4 \mathrm{~h}$ was not futile, with sperm being found in $37 \%$ of the patients.

Technique. Using an operating microscope with $\times 20-\times 40$ magnification, an equatorial incision is made at midtestis. Large vessels are carefully avoided. Once the seminiferous tubules are exposed, a systematic search is performed with the use of microscope. Larger tubules thought to contain sperm are isolated and placed into the nutrient medium, morselated and examined by and experienced embryologist or andrologist. The incision in tunica albuguinea is then closed with running prolene suture.

\section{Percutaneous epididymal sperm aspiration (PESA)}

Percutaneous epididymal sperm aspiration for intracytoplasmic sperm injection was described in 1994 by Craft and colleagues. ${ }^{124}$ It offers a relatively quick, minimally invasive and inexpensive method for sperm retrieval. Originally described in patients with $\mathrm{OA},{ }^{125}$ it remains the first choice in that group due its minimally invasive nature. Epididymal sperm offers the advantage of great maturity and motility relative to testicular sperm; a distinct advantage with regard to pregnancy outcomes has not been realized. ${ }^{126}$ The criticism of the method is that occasionally insufficient quantity of sperm is obtained. Those men are likely better managed with testicular sperm aspiration/extraction or with an open epididymal approach. Comparison between IVF-ICSI using sperm retrieved from the epididymis vs. testis has not shown significantly different fertilization or embyo transfer rates. ${ }^{127}$

Technique. The technique is similar to that of TESA. Once the testis is prepped and adequate anesthesia is obtained, the epididymis to be aspirated is held in the non-dominant hand. A 10-ml syringe with 23-gauge needle primed with nutrient medium is inserted into the epididymis and $5 \mathrm{ml}$ of negative pressure is applied. The needle should be moved back and forth inside the epididymis. Once fluid is seen just above the needle hub, it is expelled into the tube with sperm nutrient medium.

\section{Microscopic epididymal sperm aspiration (MESA)}

Similar to microTESE, MESA requires an operating microscope and proficiency in micro surgical skills. It is appropriate for men who have 
an epididymal or vasal obstruction ${ }^{128}$ and is ideal for men with unreconstructable causes of $\mathrm{OA}$ such as congenital bilateral absence of vas deference. ${ }^{129}$ MESA could also be recommended in the setting of multiple prior surgeries and extensive scarring. Even if the scarring is significant enough to obliterate the entire epididymis, sperm can still be aspirated using the same technique from the ductules between the testes and the caput epididymis. It allows identification of individual tubules and repeated, minimally traumatic aspiration of large number of spermatozoa with higher pregnancy and delivery rates compared to the sperm retrieved from testes. ${ }^{130}$ Relative to PESA, MESA offers the advantage of controlled exposure of the epididymal tubule with the ability to extract far greater quantities of motile sperm. Further, the epididymal tunica may be closed surgically to prevent ongoing sperm leakage once sperm is retrieved.

Technique. After prepping the testis and exposing the epididymis, the microscope is brought in and point with dilated tubules is identified. The epididymal tunic is exposed and a microknife or scissor is used to open a loop of the epididymal tubule. A 24-gauge angiocatheter is used to aspirate the fluid. Alternatively, a micropuncture can be done to aspirate the sperm. The puncture sites may be cauterized or closed. This technique generally allows retrieval of the sufficient amount of sperm for both cryopreservation and immediate use due to the concentrated nature of the epididymal fluid $\left(\sim 1\right.$ million sperm $\left.\mu \mathrm{l}^{-1}\right)$

\section{A COUPLE-BASED APPROACH TO THE SURGICAL TREATMENT OF MALE INFERTILITY}

Infertility is common with up to $15 \%$ of couples seeking intervention in the form of evaluation, medical therapy, surgery or the use of ART. Further, the incidence is expected to rise as more couples continue to wait until later in life to family plan. The advances of surgical and ARTs now offer more and improved options for infertile couples. Infertility treatments can be expensive, time-consuming and frequently are emotionally and physically taxing. Fortunately, infertility is rarely a lifethreatening disorder, and therefore, therapy can often be focused on the needs and desires of the patient (or couple), rather than on the threat of the disease. This 'patient-based' or 'couple-based' approach is in contrast to 'disease-based' therapies that are most commonly seen in oncological, cardiovascular, infectious and neurological disease.

The couple-based treatment approach requires a thorough evaluation of both partners in order to gain a complete understanding of the couple's fertility potential. During evaluation, factors to be assessed should focus on current fertility potential, possible reversible factors in both partners, financial and insurance circumstances, and the availability of the treatments. Through this complete assessment and with the counseling of a reproductive expert, the treatment of each couple can be tailored appropriately. Several examples of how couple-based therapy is applied with respect to surgery for male infertility are noted below.

\footnotetext{
Diagnostic surgery and surgical sperm retrieval example

For many men, the retrieval of sperm from the testicle in the case of azoospermia will not be paid for by medical insurance. However, testicular biopsy to determine the potential etiology of azoospermia is often covered. As a result, many men may elect a bilateral testicular FNA to provide a sensitive appraisal of sperm production within the testicles before embarking upon a costly and often uncertain cycle of IVF-ICSI and sperm retrieval. This approach offers the benefit of a minimally invasive procedure that can significantly refine the odds of successful sperm retrieval. Further, based upon the findings from an
}

FNA, the most appropriate and least invasive approach to sperm retrieval can be selected. In distinction to this, if cost or insurance are not barriers to care, a couple may wish to bypass such diagnostic procedures, and move straight the most definitive form of sperm retrieval, microTESE. Further, since microTESE is considered by most to offer the greatest chance of successful sperm retrieval regardless of etiology, some couples may select this option even if the odds of success are low.

\section{Surgery to improve production example}

Varicocele therapy remains a classic example of a correctable male factor that must account for the reproductive health and age or the female partner before a therapeutic plan can be implemented. Studies have suggested that when female age is controlled for, varicocele treatment is a cost effect approach to infertility therapy. Thus, in the setting of a young woman without evidence of female factors, the decision for a man to have a varicocelectomy may be clear. However, in the setting of limited female reproductive time, the best approach may be to proceed directly to IVF. Recent data have complicated this scenario by suggesting that among couples in whom the male partner has a varicocele, who ultimately undergo IVF, live birth rates are higher when the varicocele is treated. Thus, it seems that a new indication for varicocelectomy may be previously failed IVF.

\section{Surgery to improve sperm delivery example}

It is indisputable that among certain couples, reversal of vasectomy is the most cost-effective and appropriate approach to infertility treatment. ${ }^{131}$ However, in most every situation, evaluation of the female partner is critical to the reproductive success of the couple. If female reproductive time is compromised, and the use of ART is imminent, the couple should be provided the option of surgical sperm retrieval. Decreased female reproductive time also has implications in cases where VE is more likely. In these cases, men should be offered sperm retrieval and cryopreservation (from the epididymis or testis) at the time of vas reversal given that overall patency is lower, and time to patency is longer in such cases. ${ }^{132}$

\section{CONCLUSIONS}

Surgical treatment of male infertility is a constantly evolving field. Expanding diagnostic modalities, tailored treatments and improved microsurgical techniques now lead to higher patency and pregnancy rates while diminishing morbidity. The couple-based treatment approach to infertility emphasizes a thorough evaluation of both partners focusing on couple's fertility potential. It allows for tailored treatment for each couple taking into account not only medical, but also personal and financial issues and availability of treatments. While today the field of infertility treatment is more successful than ever, pregnancy is still not always achieved, possibly due to the factors that not yet known or understood.

\section{COMPETING FINANCIAL INTERESTS}

The authors would declare no competing financial interests.

1 Hull MG, Glazener CM, Kelly NJ, Conway DI, Foster PA et al. Population study of causes, treatment, and outcome of infertility. BMJ 1985; 291: 1693-7.

2 Greenhall E, Vessey M. The prevalence of subfertility: a review of the current confusion and a report of two new studies. Fertil Steril 1990; 54: 978-83.

3 Mosher WD, Pratt WF. Fecundity and infertility in the United States: incidence and trends. Fertil Steril 1991; 56: 192-3. 
4 Thonneau P, Marchand S, Tallec A, Ferial ML, Ducot B et al. Incidence and main causes of infertility in a resident population $(1,850,000)$ of three French regions (1988-1989). Hum Reprod 1991; 6: 811-6.

5 Palermo G, Joris $H$, Devroey $P$, van Steirteghem AC. Pregnancies after intracytoplasmic injection of single spermatozoon into an oocyte. Lancet 1992 340: 17-8.

6 Silber SJ, Devroey P, Tournaye H, van Steirteghem AC. Fertilizing capacity of epididymal and testicular sperm using intracytoplasmic sperm injection (ICSI). Reprod Fertil Dev 1995; 7: 281-92; discussion 292-3.

7 Vernaeve V, Tournaye H, Schiettecatte J, Verheyen G, van Steirteghem A et al. Serum inhibin $B$ cannot predict testicular sperm retrieval in patients with non-obstructive azoospermia. Hum Reprod 2002; 17: 971-6.

8 Ezeh UI, Taub NA, Moore HD, Cooke ID. Establishment of predictive variables associated with testicular sperm retrieval in men with non-obstructive azoospermia. Hum Reprod 1999; 14: 1005-12.

9 Nowroozi MR, Radkhah K, Ayati M, Jamshidian H, Ranjbaran A et al. Serum inhibin B concentration as a prognostic factor for prediction of sperm retrieval in testis biopsy of patients with azoospermia. Arch Iran Med 2008; 11: 54-6.

10 Krausz C. Male infertility: pathogenesis and clinical diagnosis. best practice \& research. Clin Endocrinol Metab 2011; 25: 271-85.

11 Schlegel PN. Causes of azoospermia and their management. Reprod Fertil Dev 2004; 16: 561-72.

12 Saleh R, Mahfouz RZ, Agarwal A, Farouk H. Histopathologic patterns of testicular biopsies in infertile azoospermic men with varicocele. Fertil Steril 2010; 94 2482-5, 2485.e1-2.

13 Obrant KO, Persson PS. Cytological study of the testis by aspiration biopsy in the evaluation of fertility. Urol Int 1965; 20: 176-89. German.

14 Turek PJ, Cha I, Ljung BM. Systematic fine-needle aspiration of the testis: correlation to biopsy and results of organ "mapping" for mature sperm in azoospermic men. Urology 1997; 49: 743-8.

15 Adhikari RC. Testicular fine needle aspiration cytology in azoospermic males. Nepal Med Coll 2009; 11: 88-91.

16 Mehrotra R, Chaurasia D. Fine needle aspiration cytology of the testis as the first-line diagnostic modality in azoospermia: a comparative study of cytology and histology. Cytopathology 2008; 19: 363-8.

17 Carpi A, Menchini Fabris FG, Palego P, Di Coscio G, Romani R, et al. Fine-needle and large-needle percutaneous aspiration biopsy of testicles in men with nonobstructive azoospermia: safety and diagnostic performance. Fertil Steril 2005; 83: 1029-33.

18 Dubin L, Amelar RD. Etiologic factors in 1294 consecutive cases of male infertility. Fertil Steril $1971 ; 22:$ 469-74

19 Chehval MJ, Purcell MH. Deterioration of semen parameters over time in men with untreated varicocele: evidence of progressive testicular damage. Fertil Steril 1992, 57: 174-7.

20 Walsh TJ, Wu AK, Croughan MS, Turek PJ. Differences in the clinical characteristics of primarily and secondarily infertile men with varicocele. Fertil Steril 2009; 91: 82630.

21 Witt MA, Lipshultz LI. Varicocele: a progressive or static lesion? Urology 1993; 42 541-3.

22 Gorelick JI, Goldstein M. Loss of fertility in men with varicocele. Fertil Steril 1993; 59: 613-6.

23 Hendin BN, Kolettis PN, Sharma RK, Thomas AJ Jr, Agarwal A. Varicocele is associated with elevated spermatozoal reactive oxygen species production and diminished seminal plasma antioxidant capacity. J Urol 1999; 161: 1831-4.

24 Sharma RK, Pasqualotto FF, Nelson DR, Thomas AJ Jr, Agarwal A. The reactive oxygen species-total antioxidant capacity score is a new measure of oxidative stress to predict male infertility. Hum Reprod 1999; 14: 2801-7.

25 Hsiao W, Rosoff JS, Pale JR, Greenwood EA, Goldstein M. Older age is associated with similar improvements in semen parameters and testosterone after subinguinal microsurgical varicocelectomy. J Urol 2011; 185: 620-5.

26 Schatte EC, Hirshberg SJ, Fallick ML, Lipschultz LI, Kim ED. Varicocelectomy improves sperm strict morphology and motility. J Urol 1998; 160: 1338-40.

27 Kibar Y, Seckin B, Erduran D. The effects of subinguinal varicocelectomy on Kruger morphology and semen parameters. J Urol 2002; 168: 1071-4.

28 Vazquez-Levin MH, Friedmann P, Goldberg SI, Medley NE, Nagler HM. Response of routine semen analysis and critical assessment of sperm morphology by Kruger classification to therapeutic varicocelectomy. J Urol 1997; 158: 1804-7.

29 Madgar I, Weissenberg R, Lunenfeld B, Karasik A, Goldwasser B. Controlled trial of high spermatic vein ligation for varicocele in infertile men. Fertil Steril 1995; 63: 120-4.

30 Dubin L, Amelar RD. Varicocelectomy: 986 cases in a twelve-year study. Urology 1977; 10: 446-9.

31 Fujisawa M, Dobashi M, Yamasaki T, Okada H, Arakawa S et al. Therapeutic strategy after microsurgical varicocelectomy in the modern assisted reproductive technology era. Urol Res 2002; 30: 195-8.

32 Chen SS, Chen LK. Predictive factors of successful varicocelectomy in infertile patients. Urol Int 2011; 86: 320-4.

33 Wu AK, Walsh TJ, Phonsombat S, Croughan MS, Turek PJ. Bilateral but not unilateral testicular hypotrophy predicts for severe impairment of semen quality in men with varicocele undergoing infertility evaluation. Urology 2008; 71 : 1114-8.

34 Steckel J, Dicker AP, Goldstein M. Relationship between varicocele size and response to varicocelectomy. J Urol 1993; 149: 769-71.

35 Jarow JP, Ogle SR, Eskew LA. Seminal improvement following repair of ultrasound detected subclinical varicoceles. J Urol 1996; 155: 1287-90.
36 McClure RD, Khoo D, Jarvi K, Hricak H. Subclinical varicocele: the effectiveness of varicocelectomy. J Urol 1991; 145: 789-91.

37 Tanrikut C, Goldstein M, Rosoff JS, Lee RK, Nelson CJ et al. Varicocele as a risk factor for androgen deficiency and effect of repair. BJU Int 2011; e-pub ahead of print 24 March 2011; doi:10.1111/j.1464-410X.2010.10030.

38 Cayan S, Kadioglu A, Orhan I, Kandirali E, Tefekli A et al. The effect of microsurgical varicocelectomy on serum follicle stimulating hormone, testosterone and free testosterone levels in infertile men with varicocele. BJU Int 1999; 84: 1046-9.

39 Diamond D. Adolescent versus adult varicoceles-how do evaluation and management differ? J Urol 2009; 181: 2418-9.

40 Robinson SP, Hampton LJ, Koo HP. Treatment strategy for the adolescent varicocele. Urol Clin North Am 2010; 37: 269-78.

41 Spinelli C, Di Giacomo M, Lo Piccolo R, Martin A, Messineo A. The role of testicular volume in adolescents with varicocele: the better way and time of surgical treatment. J Urol 2010; 184: 1722-6.

42 Poon SA, Kozakowski KA, Decastro GJ, Gjertson CK, Glassberg KI. Adolescent varicocelectomy: postoperative catch-up growth is not secondary to lymphatic ligation. J Pediatr Urol 2009; 5: 37-41.

43 Okuyama A, Fujisue H, Matsui T, Doi Y, Takeyama M et al. Surgical repair of varicocele: effective treatment for subfertile men in a controlled study. Eur Urol 1988; 14: 298-300.

44 Schlegel PN. Is assisted reproduction the optimal treatment for varicocele-associated male infertility? A cost-effectiveness analysis. Urology 1997; 49: 83-90.

45 Inci K, Hascicek M, Kara O, Dikmen AV, Gurgan T et al. Sperm retrieval and intracytoplasmic sperm injection in men with nonobstructive azoospermia, and treated and untreated varicocele. J Urol 2009; 182: 1500-5.

46 Evers JH, Collins J, Clarke J. Surgery or embolisation for varicoceles in subfertile men. Cochrane Database Syst Rev 2008; 3: CD000479.

47 Marmar JL, Agarwal A, Prabakaran S, Agarwal R, Short RA et al. Reassessing the value of varicocelectomy as a treatment for male subfertility with a new meta-analysis. Fertil Steril 2007; 88: 639-48

48 Weedin JW, Khera M, Lipshultz LI. Varicocele repair in patients with nonobstructive azoospermia: a meta-analysis. J Urol 2010; 183: 2309-15.

49 Lukkarinen $\mathrm{O}$, Hellstrom $\mathrm{P}$, Leinonen S, Juntunen $\mathrm{K}$. Is varicocele treatment useful? Ann Chir Gynaecol 1997; 86: 40-4.

50 Negri L, Levi-Setti PE. Pregnancy rate after varicocele repair: how many miscarriages? J Androl 2011; 32: 1.

51 Walsh TJ, Wu AK, Croughan MS, Turek PJ. Differences in the clinical characteristics of primarily and secondarily infertile men with varicocele. Fertil Steril 2009; 91: 82630.

52 Practice Committee of the American Society for Reproductive Medicine. Report on varicocele and infertility. Fertil Steril 2004; 82(Suppl 1): S142-5.

53 Palomo A. Radical cure of varicocele by a new technique; preliminary report. J Urol 1949; 61: 604-7.

54 Chan PT, Wright EJ, Goldstein M. Incidence and postoperative outcomes of accidental ligation of the testicular artery during microsurgical varicocelectomy. J Urol 2005; 173: 482-4.

55 Tauber R, Pfeiffer D. Surgical atlas varicocele: Antegrade scrotal sclerotherapy. BJU Int 2006; 98: 1333-44.

56 Tauber R, Johnsen N. Antegrade scrotal sclerotherapy for the treatment of varicocele: technique and late results. J Urol 1994; 151: 386-90.

57 Zaupa P, Mayr J, Hollwarth ME. Antegrade scrotal sclerotherapy for treating primary varicocele in children. BJU Int 2006; 97: 809-12.

58 Ficarra V, Porcaro AB, Righetti R, Cerruto MA, Pilloni S et al. Antegrade scrotal sclerotherapy in the treatment of varicocele: a prospective study. BJU Int 2002 , 89: 264-8.

59 Beutner S, May M, Hoschke B, Helke C, Lein M et al. Treatment of varicocele with reference to age: a retrospective comparison of three minimally invasive procedures. Surg Endosc 2007; 21: 61-5.

$60 \mathrm{Li} \mathrm{L}$, Zeng XQ, Li YH. Digital subtraction angiography-guided percutaneous transcatheter foam sclerotherapy of varicocele: a novel tracking technique. AJR Am J Roentgenol 2009; 193: 978-80.

61 Goldstein M. Vasectomy reversal. Compr Ther 1993; 19: 37-41.

62 Shridharani A, Sandlow JI. Vasectomy reversal versus IVF with sperm retrieval: which is better? Curr Opin Urol 2010; 20: 503-9.

63 Gerrard ER Jr, Sandlow JI, Oster RA, Burns JR, Box LC et al. Effect of female partner age on pregnancy rates after vasectomy reversal. Fertil Steril 2007; 87: 1340-4.

64 Hinz S, Rais-Bahrami S, Kempkensteffen C, Weiske WH, Schrader M et al. Fertility rates following vasectomy reversal: importance of age of the female partner. Urol Int 2008; 81: 416-20.

65 Hsieh MH, Meng MV, Turek PJ. Markov modeling of vasectomy reversal and ART for infertility: how do obstructive interval and female partner age influence cost effectiveness? Fertil Steril 2007; 88: 840-6.

66 Silber SJ. Microsurgery in clinical urology. Urology 1975; 6: 150-3.

67 Silber SJ. Pregnancy after vasovasostomy for vasectomy reversal: a study of factors affecting long-term return of fertility in 282 patients followed for 10 years. Hum Reprod 1989; 4: 318-22.

68 Belker AM, Thomas AJ Jr, Fuchs EF, Konnak JW, Sharlip ID. Results of 1,469 microsurgical vasectomy reversals by the Vasovasostomy Study Group. J Urol 1991; 145: 505-11.

69 Fuchs EF, Burt RA. Vasectomy reversal performed 15 years or more after vasectomy: correlation of pregnancy outcome with partner age and with pregnancy results of in 
vitro fertilization with intracytoplasmic sperm injection. Fertil Steril 2002; 77 : 516-9.

70 Hernandez J, Sabanegh ES. Repeat vasectomy reversal after initial failure: overall results and predictors for success. J Urol 1999; 161: 1153-6.

71 Fox M. Vasectomy reversal-microsurgery for best results. Br J Urol 1994; 73: 449-53.

72 Dewire DM, Lawson RK. Experience with macroscopic vasectomy reversal at the Medical College of Wisconsin. Wis Med J 1994; 93: 107-9.

73 Jee SH, Hong YK. One-layer vasovasostomy: microsurgical versus loupe-assisted. Fertil Steril 2010; 94: 2308-11.

74 Matthews GJ, Schlegel PN, Goldstein M. Patency following microsurgical vasoepididymostomy and vasovasostomy: temporal considerations. J Urol 1995; 154: 2070-3.

75 Fischer MA, Grantmyre JE. Comparison of modified one- and two-layer microsurgical vasovasostomy. BJU Int 2000; 85: 1085-8.

76 Sharlip ID. Vasovasostomy: comparison of two microsurgical techniques. Urology $1981 ; 17: 347-52$

77 Sigman $M$. The relationship between intravasal sperm quality and patency rates after vasovasostomy. J Urol 2004; 171: 307-9.

78 Goldstein M, Li PS, Matthews GJ. Microsurgical vasovasostomy: the microdot technique of precision suture placement. J Urol 1998; 159: 188-90.

79 Eisenberg ML, Walsh TJ, Turek PJ. Use of viscoelastic solution to improve visualization during urologic microsurgery: evaluation of patency after vasovasostomy. Urology 2009; 73: 134-6.

80 Martin E, Carnett JB, Levi JV, Pennington ME. The surgical treatment of sterility due to obstruction at the epididymis; together with a study of the morphology of human spermatozoa. Univ Pa Med Bull 1902; 15: 2-15.

81 Silber SJ. Microscopic vasoepididymostomy: specific microanastomosis to the epididymal tubule. Fertil Steril 1978; 30: 565-71.

82 Berger RE. Triangulation end-to-side vasoepididymostomy. J Urol 1998; 159: 1951-3

83 Thomas AJ Jr. Infertility. J Urol 2004; 172: 829-30.

84 Lipshultz LI, Rumohr JA, Bennett RC. Techniques for vasectomy reversal. Urol Clin North Am 2009; 36: 375-82.

85 Kumar R, Mukherjee S, Gupta NP. Intussusception vasoepididymostomy with longitudinal suture placement for idiopathic obstructive azoospermia. J Urol 2010 ; 183: 1489-92

86 Marmar JL, Sharlip I, Goldstein M. Results of vasovasostomy or vasoepididymostomy after failed percutaneous epididymal sperm aspirations. J Urol 2008; 179: 1506-9.

87 Kuang W, Shin PR, Oder M, Thomas AJ Jr. Robotic-assisted vasovasostomy: a twolayer technique in an animal model. Urology 2005; 65: 811-4.

88 Parekattil SJ, Cohen MS. Robotic surgery in male infertility and chronic orchialgia. Curr Opin Urol 2010; 20: 75-9.

89 Pryor JP, Hendry WF. Ejaculatory duct obstruction in subfertile males: analysis of 87 patients. Fertil Steril 1991; 56: 725-30.

90 Littrup PJ, Lee F, McLeary RD, Wu D, Lee A et al. Transrectal US of the seminal vesicles and ejaculatory ducts: clinical correlation. Radiology 1988; 168: 625-8.

91 Schroeder-Printzen I, Ludwig M, Kohn F, Weidner W. Surgical therapy in infertile men with ejaculatory duct obstruction: technique and outcome of a standardized surgical approach. Hum Reprod 2000; 15: 1364-8.

92 Farley S, Barnes R. Stenosis of ejaculatory ducts treated by endoscopic resection. J Urol 1973; 109: 664-6.

93 Purohit RS, Wu DS, Shinohara K, Turek PJ. A prospective comparison of 3 diagnostic methods to evaluate ejaculatory duct obstruction. J Urol 2004; 171: 232-5; discussion 235-6.

94 Kadioglu A, Cayan S, Tefekli A, Orhan I, Engin G et al. Does response to treatment of ejaculatory duct obstruction in infertile men vary with pathology? Fertil Steril 2001; 76: $138-42$

95 Pryor JP, Hendry WF. Ejaculatory duct obstruction in subfertile males: analysis of 87 patients. Fertil Steril 1991; 56: 725-30.

96 Farley S, Barnes R. Stenosis of ejaculatory ducts treated by endoscopic resection. J Urol 1973; 109: 664-6.

97 Turek PJ, Magana JO, Lipshultz LI. Semen parameters before and after transurethral surgery for ejaculatory duct obstruction. J Urol 1996; 155: 1291-3.

98 Willott GM. Frequency of azoospermia. Forensic science international 1982; 20: 9-10.

99 Jarow JP, Espeland MA, Lipshultz LI. Evaluation of the azoospermic patient. J Urol 1989; 142: 62-5.

100 Matsumiya K, Namiki M, Takahara S, Kondoh N, Takada S et al. Clinical study of azoospermia. Int J Androl 1994; 17: 140-2.

101 Schoor RA, Elhanbly S, Niederberger CS, Ross LS. The role of testicular biopsy in the modern management of male infertility. J Urol 2002; 167: 197-200.

102 Belker AM, Sherins RJ, Dennison-Lagos L, Thorsell LP, Schulman JD. Percutaneous testicular sperm aspiration: a convenient and effective office procedure to retrieve sperm for in vitro fertilization with intracytoplasmic sperm injection. J Urol 1998; 160: 2058-62.

103 Borges E Jr, Braga DP, Bonetti TC, Pasqualotto FF, laconelli A Jr. Predictive factors of repeat sperm aspiration success. Urology 2010; 75: 87-91.

104 Devroey P, Liu J, Nagy Z, Tournaye H, Silber SJ et al. Normal fertilization of human oocytes after testicular sperm extraction and intracytoplasmic sperm injection. Fertil Steril 1994; 62: 639-41.
105 Devroey P, Liu J, Nagy Z, Goossens A, Tournaye H et al. Pregnancies after testicular sperm extraction and intracytoplasmic sperm injection in non-obstructive azoospermia. Hum Reprod 1995; 10: 1457-60.

106 Tournaye H, Liu J, Nagy Z, Joris H, Wisanto A et al. Intracytoplasmic sperm injection (ICSI): the Brussels experience. Reprod Fertil Dev 1995; 7: 269-78; discussion 278-9.

107 Donoso P, Tournaye H, Devroey P. Which is the best sperm retrieval technique for nonobstructive azoospermia? A systematic review. Hum Reprod Update 2007; 13 . 539-49.

108 Hauser R, Botchan A, Amit A, Ben Yosef D, Gamzu R et al. Multiple testicular sampling in non-obstructive azoospermia-is it necessary? Hum Reprod 1998; 13: 3081-5.

109 Tash JA, Schlegel PN. Histologic effects of testicular sperm extraction on the testicle in men with nonobstructive azoospermia. Urology 2001; 57: 334-7.

110 Amer M, Haggar SE, Moustafa T, Abd El-Naser T, Zohdy W. Testicular sperm extraction: impact of testicular histology on outcome, number of biopsies to be performed and optimal time for repetition. Hum Reprod 1999; 14: 3030-4.

111 Schlegel PN, Su LM. Physiological consequences of testicular sperm extraction. Hum Reprod 1997; 12: 1688-92.

112 Schlegel PN, Li PS. Microdissection TESE: sperm retrieval in non-obstructive azoospermia. Hum Reprod Update 1998; 4: 439

113 Schlegel PN. Testicular sperm extraction: microdissection improves sperm yield with minimal tissue excision. Hum Reprod 1999; 14: 131-5.

114 Okada H, Dobashi M, Yamazaki T, Hara I, Fujisawa M et al. Conventional versus microdissection testicular sperm extraction for nonobstructive azoospermia. J Urol 2002; 168: 1063-7.

115 Schlegel PN. Male infertility: evaluation and sperm retrieval. Clin Obstet Gynecol 2006; 49: 55-72.

116 Silber SJ. Microsurgical TESE and the distribution of spermatogenesis in nonobstructive azoospermia. Hum Reprod 2000; 15: 2278-84.

117 Ramasamy R, Yagan N, Schlegel PN. Structural and functional changes to the testis after conventional versus microdissection testicular sperm extraction. Urology 2005; 65: 1190-4.

118 Mulhall JP, Ghaly SW, Aviv N, Ahmed A. The utility of optical loupe magnification for testis sperm extraction in men with nonobstructive azoospermia. J Androl 2005; 26: $178-81$.

119 Turunc T, Gul U, Haydardedeoglu B, Bal N, Kuzgunbay B et al. Conventional testicular sperm extraction combined with the microdissection technique in nonobstructive azoospermic patients: a prospective comparative study. Fertil Steril 2010; 94: 2157-60.

120 Okubo K, Ogura K, Ichioka K, Terada N, Matsuta Y et al. Testicular sperm extraction for non-obstructive azoospermia: results with conventional and microsurgical techniques. Hinyokika Kiyo 2002; 48: 275-80. Japanese.

121 Tsujimura A, Miyagawa Y, Takao T, Takada S, Koga M et al. Salvage microdissection testicular sperm extraction after failed conventional testicular sperm extraction in patients with nonobstructive azoospermia. J Urol 2006; 175: 1446-9; discussion 1449.

122 Tsujimura A, Matsumiya K, Miyagawa Y, Tohda A, Miura H et al. Conventional multiple or microdissection testicular sperm extraction: a comparative study. Hum Reprod 2002; 17: 2924-9

123 Ramasamy R, Fisher ES, Ricci JA, Leung RA, Schlegel PN. Duration of microdissection testicular sperm extraction procedures: relationship to sperm retrieval success. J Urol 2011; 185: 1394-7.

124 Tsirigotis M, Bennett V, Nicholson N, Khalifa Y, Hogewind G et al. Experience with subzonal insemination (SUZI) and intracytoplasmic sperm injection (ICSI) on unfertilized aged human oocytes. J Assist Reprod Genet 1994; 11: 389-94.

125 Shrivastav P, Nadkarni P, Wensvoort S, Craft I. Percutaneous epididymal sperm aspiration for obstructive azoospermia. Hum Reprod 1994; 9: 2058-61.

126 Buffat C, Patrat C, Merlet F, Guibert J, Epelboin S et al. ICSI outcomes in obstructive azoospermia: influence of the origin of surgically retrieved spermatozoa and the cause of obstruction. Hum Reprod 2006; 21: 1018-24.

127 Pasqualotto FF, Rossi-Ferragut LM, Rocha CC, laconelli A Jr, Borges E Jr. Outcome of in vitro fertilization and intracytoplasmic injection of epididymal and testicular sperm obtained from patients with obstructive and nonobstructive azoospermia. J Urol2002; 167: 1753-6

128 Matthews GJ, Goldstein M. A simplified method of epididymal sperm aspiration. Urology 1996; 47: 123-5.

129 Tournaye H, Devroey P, Liu J, Nagy Z, Lissens W et al. Microsurgical epididymal sperm aspiration and intracytoplasmic sperm injection: a new effective approach to infertility as a result of congenital bilateral absence of the vas deferens. Fertil Steril 1994; 61 : 1045-51.

130 Silber SJ. Sperm retrieval for azoospermia and intracytoplasmic sperm injection success rates-a personal overview. Hum Fertil (Camb) 13: 247-56

$131 \mathrm{Hsieh}$ MH, Meng MV, Turek PJ. Markov modeling of vasectomy reversal and ART for infertility: how do obstructive interval and female partner age influence cost effectiveness? Fertil Steril 2007; 88: 840-6.

132 Yang G, Walsh TJ, Shefi S, Turek PJ. The kinetics of the return of motile sperm to the ejaculate after vasectomy reversal. J Urol 2007; 177: 2272-6.

133 Harris SE, Sandlow JI. Sperm acquisition in nonobstructive azoospermia: what are the options? Urol Clin North Am 2008; 35: 235-42, ix

134 Diegidio P, Jhaveri JK, Ghannam S, Pinkhasov R, Shabsigh R et al. Review of current varicocelectomy techniques and their outcomes. BJU Int 2011; 108: 1152-72. 